\title{
تطوير المواد التعليمية لكتاب اللغة العربية للناشئين باعتماد المفردات
}

\section{Nahdiyatul Ummah, M.Pd.I}

almasalfin@.gmail.com

MALIA FRANSISCA

MALIAFRANSISCA2018@gmail.com

\section{IAI SUNAN GIRI BOJONEGORO}

\begin{abstract}
Abstrac
In the book al-Arabiyyah lin-Nasyi'in for students there is a discussion about plural words but only a few. In vocabulary learning requires an understanding of all the words in a reading which the student is then able to change it from a single word to in plural it. This paper written on the basis of the needs of students in the boarding school MAS Sidoarjo because of the students feel difficult currently working on the final project in class 3 Aliyah or senior high school. The last task their final form of writing vocabulary in Arabic as many 1.200 words. Which consists of 510 noun, 390 verb, 180 adjective, 60 preposition, and 60 idiom of. The format of writing vocabulary (for example taken a point noun) include: number, noun single, noun plural, example in a sentences and references. In the point noun plural this is the students feel difficult look for it.
\end{abstract}

Keyword : Vocabulary, Plural Word, Single Word
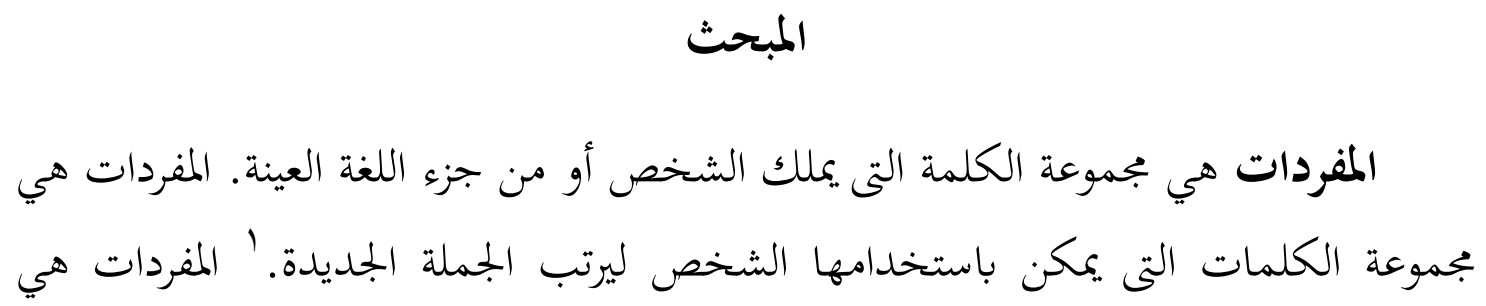

${ }^{1}$ http://id.m.wikipedia.org/wiki/Kosakata 


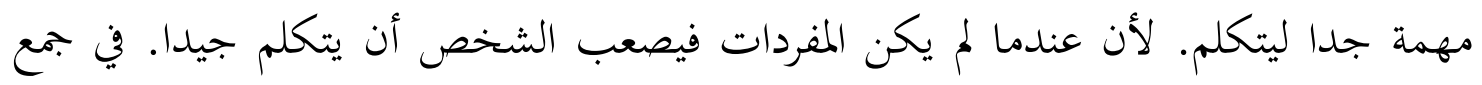

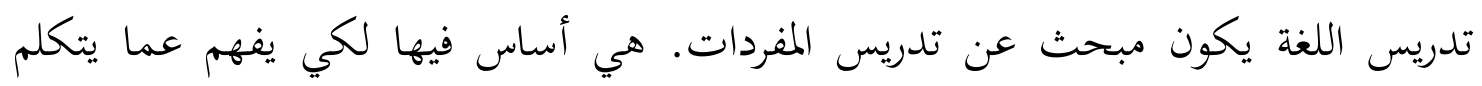

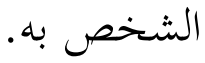

المفردات هي خزينة الكلمة. `يجب على الشخص أن يكون جهار الكلمات كثيرة ليستطيع اللغة المعينة مثل العربية. قال رشدي أحمد طعيمة عن أنواع المفردات وأسس اختيات الشيارها

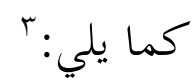

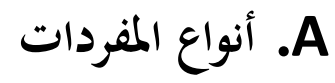
أ. تقسيمها حسب المهارات اللغوية ( ) مفردات للفهم

ه الاستماع ويقصد بذلك بمموع الكلمات التى يستطيع الفرد التعرف عليها وفهمها عندما يتلقاها من أحد المتحدثين.

ه القراءة ويقصد بذلك بجموع الكلمات التى يستطيع الفرد التعرف عليها وفهمها عندما يتصل بها على صفحة مطبوعة. r (r) مفردات للكلام

عادية ويقصد بذلك بمموع الكلمات التى يستخدمها الفرد في حياته اليومية.

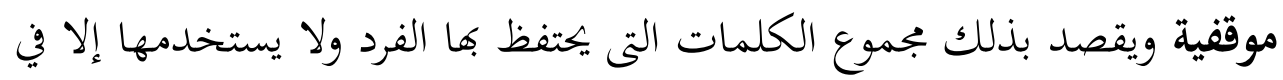
بما موقف معين أو عندما تكن له مناسبة.

ه عادية ويقصد بذلك مجموع الكلمات التى يستخدمها الفرد في موقف الاتصال الكتابي الشخصى مثل أخذ مذكرات، كتابة يوميات... إلخ.

${ }^{2}$ Risa Agustin, "Kamus Ilmiah Populer Lengkap", (Surabaya: Serba Jaya, Tanpa Tahun), hlm: 263.

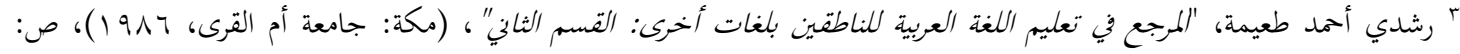


موقفية ويقصد بذلك بجموع الكلمات التى يستخدمها الفرد في موقف الاتصال الكتابي الرسمي مثل تقديم طلب للعمل أو استقالة أو كتابة تقرير ... إلخ.

$$
\text { צ) مفردات كامنة }
$$

• سياقية ويقصد بذلك مجموع الكلمات التى يمكن تفسيرها من السياق الذي

$$
\text { وردت فيه. }
$$

• تحليلية ويقصد بذلك مجموع الكلمات التى يمكن تفسيرها استنادا إلى خصائصها

$$
\text { ب. تقسيمها حسب المعنى مأن ما نريد عليها من حروف أو ما نقص. }
$$

كلمات الختوى ويقصد بها بجموع المفردات الأساسية التى تشكل صلب الرسالة

$$
\text { مثل الأسماء والأفعال.... إلخ. }
$$

كلمات وظيفية ويقصد بها بجموع المفردات التى تربط المفردات والجمل والتى التهات التمات يستعان بما على إتمام الرسالة مثل حروف الجر والعطف وأدوات الاستفهام

$$
\text { وأدوات الربط بشكل عام. }
$$

كلمات عنقودية ويقصد بها بجموع المفردات التى لا تنقل معنا معينا وهي

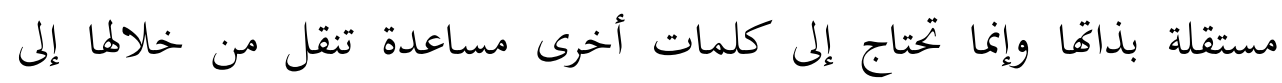
المستقبل معنى خاصا مثل "رغب" فهذه الكلمة تكون بمعنى أحب في قولنا:

$$
\text { ج. تقسيمها حسب التخصص في تكون بمعنى انصرف في قولنا: رغب عن. }
$$

كلمات خادمة ويقصد بها بجموع الكلمات العامة التى يستخدمها الفرد في موقف الحياة العادية أو استخدمته الرسمية غير التخصصية.

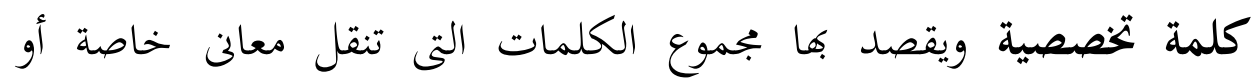

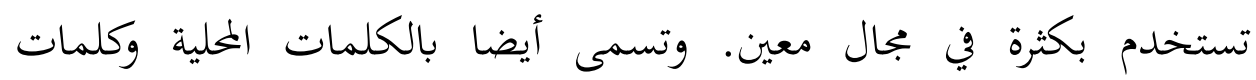

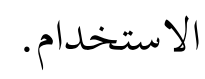
د. تقسيمها حسب الاستخدام 
كلمات نشيطة ويقصد بها مجموع المفردات التى يكثر الفرد من استعمالها في الكلام أو في الكتابة أو حتى يسمعها أو يقرؤها بكثرة.

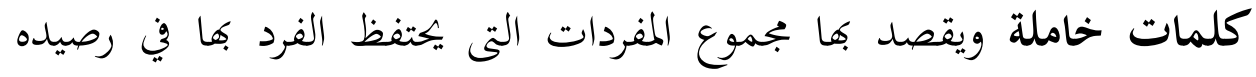
اللغوى وإن لم يستعملها. وهذا النوع من المفردات يفهم الفرد ولالاته واستخداماته عند ما يظهر له على الصفحة المطبوعة أو يصل إلى سمعه.

$$
\text { B }
$$

1. التوافر: نفضل الكلمة شائعة الاستخدام على غيرها ما دامت متفقة معها في المعنى. وتستشار فيها قوائم المفردات التى أجرت حصرا للكلمات المستعملة وبينت معدل تكرار كل منها.

ץ. التوزع أو المدى: تفضل الكلمة التى تستخدم في أكثر من بلد عربي أو على تلك

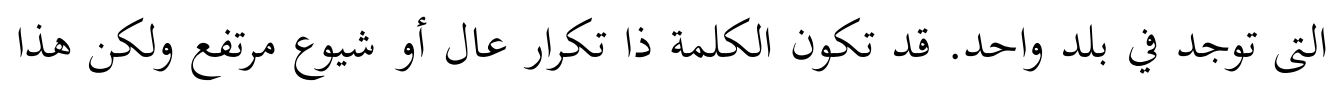
التكرار المرتفع ينحصر في بلد واحد. لذا يفضل أن تختار الكلمة التى تلتقى بنظم

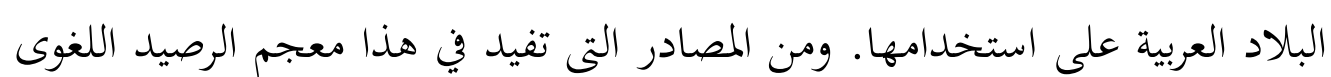
للطفل العربي والذي أعدته المنظمة العربية للتربية والثقافة والعلوم بتونس والذي كان النيان للكاتب شرف الاشتراك في إعداده. ويضم الكلمات التى وردت على ألسنة الأطفال

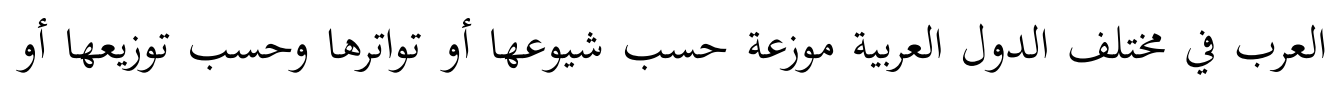
مداها. "ا. المتاحية: تفضل الكلمة التى تكون في متناول الفرد يجدها حين يطلبها والتى تؤدى له معنى محددا. ويقاس هذا لسؤال الناس عن الكلمات التى يستخدمونا في مجالات معينة.

؛. الألفة: تفضل الكلمة التى تكون مألوفة عند الأفراد على الكلمة المهجورة نادرة الاستخدام. فكلمة "شمس" تفضل بلاشك كلمة "ذكاء" وإن كانا متفقين في المعنى. ๑ـ الشمول: تفضل الكلمة التى تغطى عدة بجالات في وقت واحد عن تلك التى لا لا

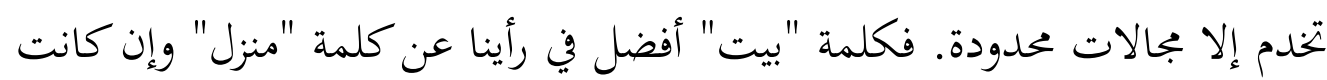


بينهما فروق دقيقة إلا أها فروق لا قم الدارس في المستويات المبتدئة خاصة. إن كلمة "بيت" تعطى عددا أكبر من المجالات ولننظر في هذه الاستخدامات: بيتمات فيتا، بيت الله، بيت الإبراه "البوصلة"، بيت العنكبوت، بيت القصيد.... إلخ.

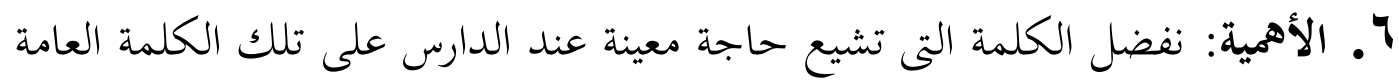
التى قد لا يحتاجها أو يحتاجها قليلا. V. العروبة: تفضل الكلمة العربية على غيرها... و.بهذا المنطق يفضل تعليم الدارس كلمة

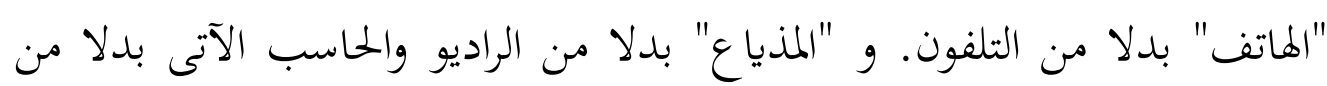

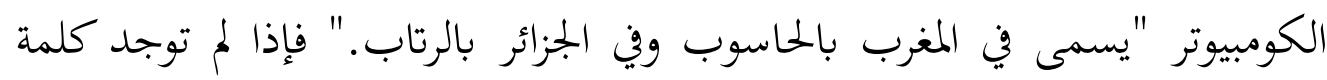
عربية تفضل الكلمة المعربة مثل: التلفاز على التلفزيون، وأخيرا تأتى الكلمة الأجنبية التى لا تقابل لها في العربية، على أن تكتب بالطبع بالحرف العربي مثل "فيديو." بعد دراسة المفردات، يحتاج الطلاب إلى الاختبار. هذه هي الاختبارات للمفردات عند الدكتور محمد علي الخولي: أختبء المثل: املأ الفراغ بكلمة واحدة من عندك. أعلى نقطة في الجبل تدعى ........................... المنطقة السفلى في البحر تدعى لـ......................... ه الدواء الذي يستعمل ضد الجراثيم تدعى المضاد ....

$$
\text { r }
$$

المثل: ضع دائرة حول حرف الكلمة المترادف للكلمة التى تحتها الخط: إنمرديا: إنه رجل ثري. 


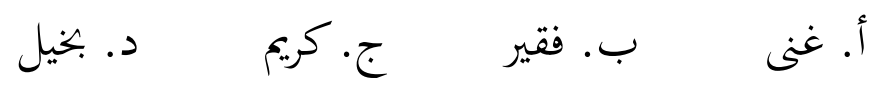

$$
\text { الحرب والليل والبيداء تعرفه. }
$$

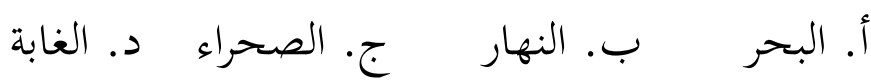

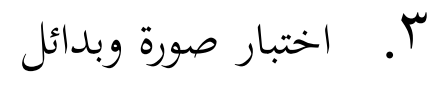

المثل: ضع دائرة حول حرف الكلمة التى تناسب الصورة المحاذية.

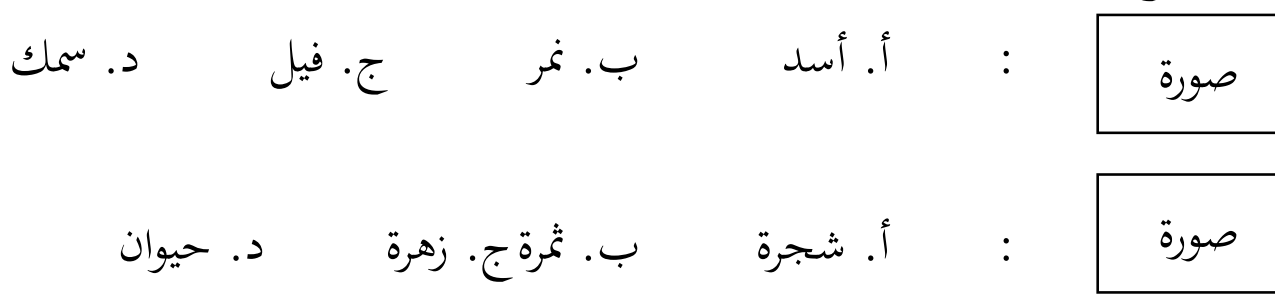$$
\text { ع. ـ اختبار تعريف وبدائل }
$$$$
\text { المثل: ضع دائرة حول حرف البديل الصحيح. }
$$$$
\text { • الشخص الذي يستلم النقود من المشترى هو ... }
$$

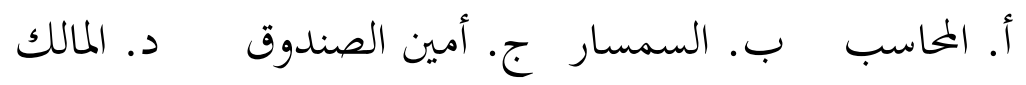

طرد الهواء من الرئتين في أثناء التنفس هو ...

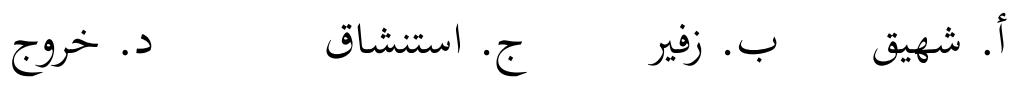

$$
\begin{aligned}
& \text { 0. اختبار كلمة وتعريفات } \\
& \text { المثل: ضع دائرة حول حرف البديل الصحيح. } \\
& \text { التنفس هو... } \\
& \text { أ. عملية تأخذ ثاني أكسد الكربون وتخرج الأكسجين } \\
& \text { ب. عملية تأخذ النتروجين وتخرج الأكسجين } \\
& \text { ج. عملية تأخذ الهيدروجين وتخرج الأكسجين } \\
& \text { د. عملية تأخذ الأكسجين وتخرج ثاني أكسد الكربون }
\end{aligned}
$$

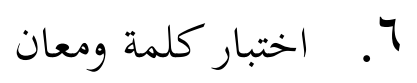

المثل: اختر البديل الصحيح لمعنى الكلمة التى تحتها الخط وضع دائرة حول حروف 


$$
\text { • • أغمر المطر ليلة أمس. }
$$

المثل: ضع خطا تحت كلمة واحدة في كل بجموعة بحيث تقترن تلك الكلمة مع الكلمة

$$
\begin{aligned}
& \text { الرئيسية. }
\end{aligned}
$$

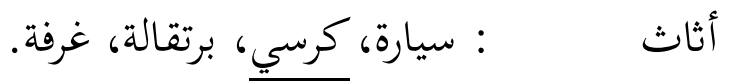

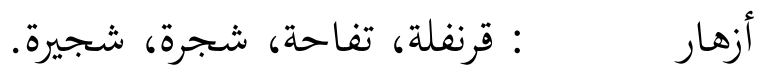

$$
\begin{aligned}
& \text { قرطاسية آلة، كتاب، فكرة، قلم. }
\end{aligned}
$$

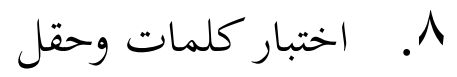

$$
\begin{aligned}
& \text { المثل: ضع أمام كل مجموعة من الكلمات الحقل الذي تنتمى إليه: }
\end{aligned}
$$

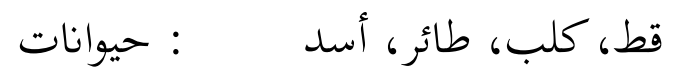

$$
\begin{aligned}
& \text { ق قلم، مسطرة، مساحة، ورقة } \\
& \text { 9. اختبار كلمات وفراغات } \\
& \text { المثل: املأ الفراغ بالكلمة المناسبة: إنبار وفراعاث } \\
& \text { تأكل - يريد - تشرب - أتمنى - تفضل }
\end{aligned}
$$

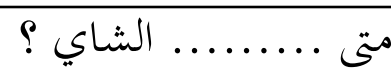

$$
\begin{aligned}
& \text { ه................ أن أكون مهندسا. } \\
& \text { ه أ........... الطب أم الهندسة ؟ } \\
& \text { فاطمة لا ........... البيض. }
\end{aligned}
$$

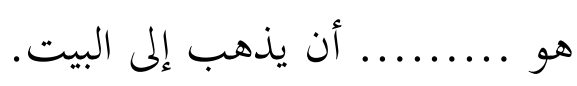

$$
\begin{aligned}
& \text { • ل إختبار مزاوجة }
\end{aligned}
$$

المثل: ضع أمام كل كلمة في القائمة الأولى رقم الكلمة المرادفة لها من القائمة الثانية:

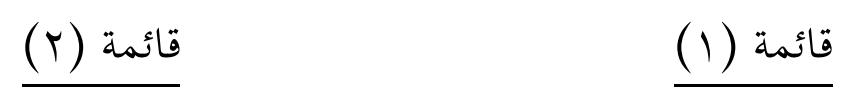

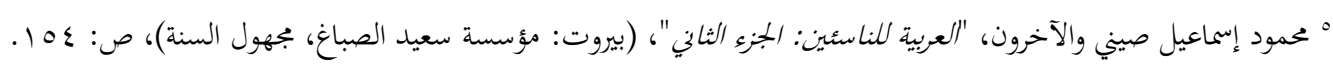




$$
\begin{aligned}
& \text { ا ـ قاحلة } \\
& \text { ….... } \\
& \text { مكتظ ......... }
\end{aligned}
$$

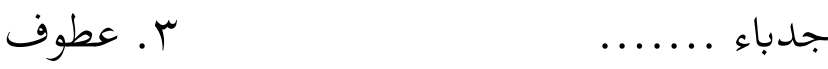

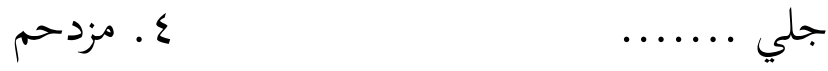

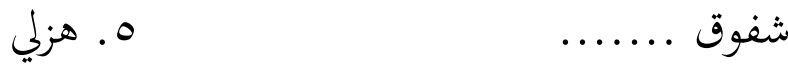

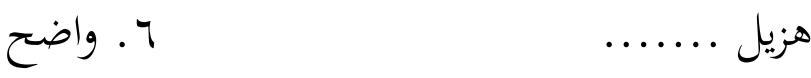

$$
\begin{aligned}
& \text { V . V }
\end{aligned}
$$

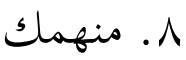

$$
\begin{aligned}
& \text { ا (اختبار الاستعمال في جملة } \\
& \text { المثل: استعمل الكلمات الآتية في جمل مفيدة من عندك: }
\end{aligned}
$$

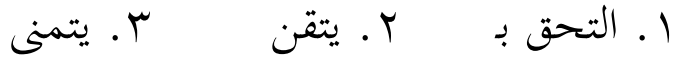

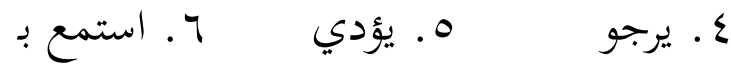

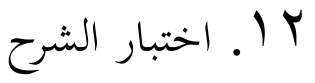

$$
\begin{aligned}
& \text { المثل: اشرح معنى كل كلمة مما يلي: }
\end{aligned}
$$

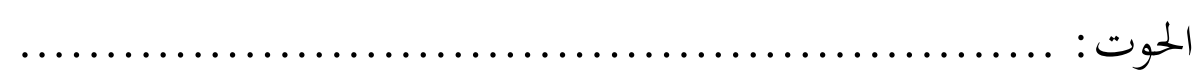

$$
\begin{aligned}
& \text { الحنجرة } \\
& \text { ب ا ـ اختبار الاشتقاق } \\
& \text { المثل: اشرح معنى كل كلمة مما يلي: }
\end{aligned}
$$

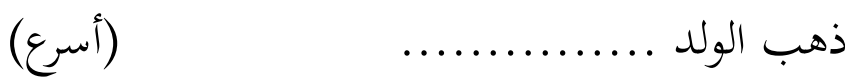

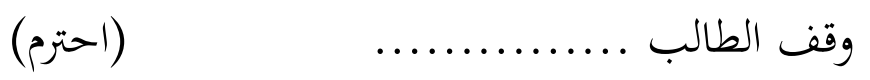

$$
\begin{aligned}
& \text { يستخدم .................. لتوجيه السيارة. (قاد) } \\
& \text { ع ا ـ اختبار ملء الغراغ المعان }
\end{aligned}
$$

" محمود إسماعيل صيني والآخرون، "العربية للناسئن: الجزء الرابع"، (بيروت: مؤسسة سعيد الصباغ، مجهول السنة)، ص: Vو. 
المثل: املأ الفراغ بكلمة مناسبة مع التقليد بأول حرف مذكور: ه إنه جندي ج. ................. لا يخاف. هالد بن الوليد ق ق................ ذكي.

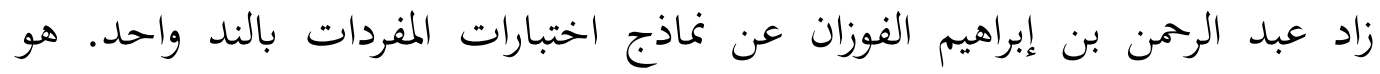

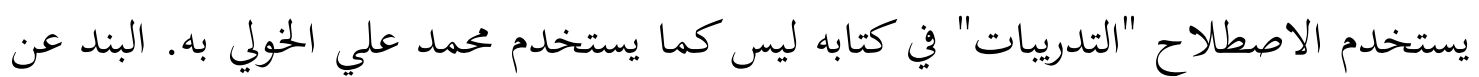

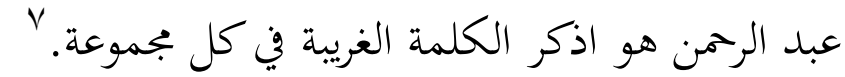

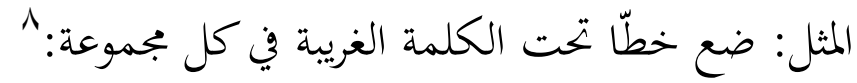
1. الطائرات - الصحف - الساعات - المجلات.

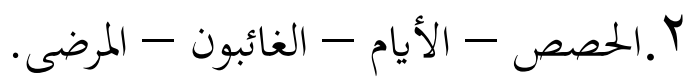

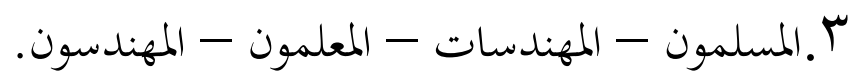

نموذج تطوير المواد التعليمية لتدريس المفردات

جدول المفردات للأسماء في كتاب اللغة العربية للناشئين الجزء الثاني

\begin{tabular}{|c|c|c|c|c|}
\hline 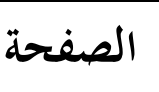 & 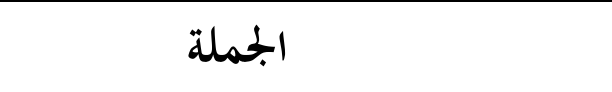 & 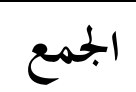 & 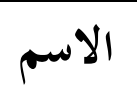 & 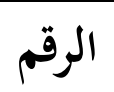 \\
\hline 7 & وقف التلاميذ & تلاميذ & تلميذ & 1 \\
\hline 7 & اللغة العربية أربع حصص في الأسبوع & حصص & حصة - la & r \\
\hline 1 & جلس التلاميذ على الكراسي & 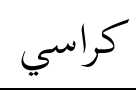 & 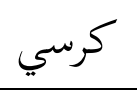 & $r$ \\
\hline 11 & وأنا سنبقى ثمانية أيام تقريبا & أيام & يوم & $\varepsilon$ \\
\hline 10 & ارتدى أحمد ملابس الإحرام & 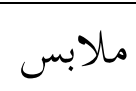 & 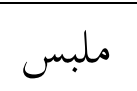 & ○ \\
\hline rq & وصل الأولاد قبل قليل & 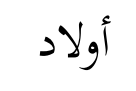 & ولد & 7 \\
\hline rq & هو يسقى أشجار الحديقة & أشجار & شجرة & v \\
\hline rr & في الحديقة أشجار كثيرة وزهور جميلة & زهور & 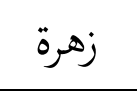 & $\wedge$ \\
\hline
\end{tabular}

ل عبد الرحمن بن إبراهيم الفوزان، "إعداد مواد تعليم اللغة العربيّة لغير الناطقين بها" ، (بجهول المكان والطبيعة، مبع ا هـ)، ص: 90.

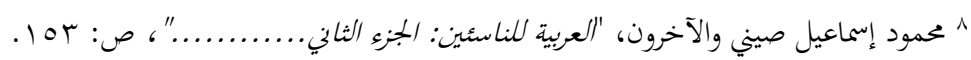




\begin{tabular}{|c|c|c|c|c|}
\hline r & عمر يراجع دروسه & 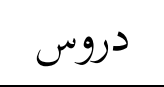 & 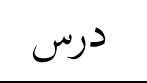 & 9 \\
\hline rr & والأم تقرأ بعض الصحف والمجلات & صحف & صحيفة & 1 . \\
\hline $0 \wedge$ & في حقيبتي كتب ودفاتر وأقلام & 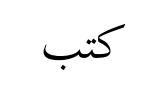 & 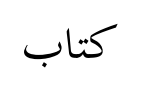 & 11 \\
\hline $0 \wedge$ & في حقيبتي كتب ودفاتر وأقلام & 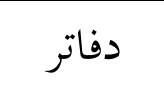 & دفتر & IT \\
\hline $0 \wedge$ & في حقيتي كتب ودفاتر وأقلام & أقلام & 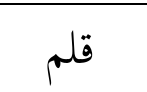 & ir \\
\hline$T V$ & سافر حسن إلى السعودية قبل ثلاث سنوات & سنوات & سنة & $1 \varepsilon$ \\
\hline$T V$ & ويفهم أحاديث الرسول & 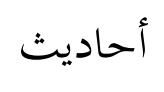 & حديث & 10 \\
\hline $7 V$ & وهو يكتب الرسائل إلى أصدقائه & 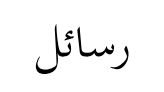 & 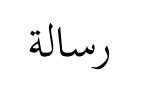 & 17 \\
\hline $7 V$ & وهو يكتب الرسائل إلى أصدقائه & أصدقاء & صديق & iv \\
\hline VT & أنا أصل في عشر دقائق & 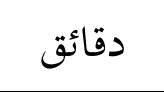 & دقيقة & 11 \\
\hline 9 . & هذا مسجد وهذه حديقة الحيوانات & 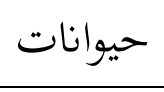 & 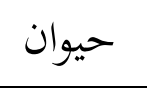 & 19 \\
\hline 9. & أنت تستعملين ألوانا جميلة يا مريم & ألوان & 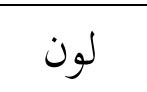 & $r$. \\
\hline
\end{tabular}

\section{الخاتمة}

تحفيظ المفردات مهم جدا لتفهم اللغة. لأن هدف اللغة هو التكلم مع الآخر. عندما

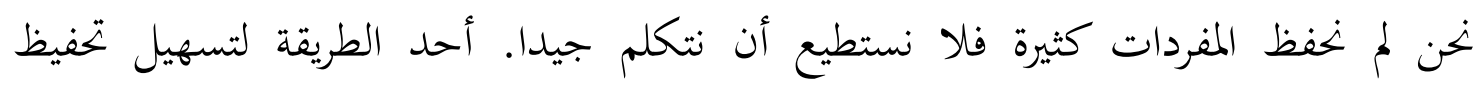
المفردات هي بتعريف جمعها. لأن لم يكتب مؤلف الكتاب المفرد وحده ولكن الجمع أيضا. فلذك، يجب على الطلاب أن يجفظوا الجمع أيضا. بتكوين جدوال المفردات، لعل الطلاب يشعرون سهال. آمين.

\section{المراجع}




$$
\begin{aligned}
& \text { طعيمة، رشدي أحمد. المرجع في تعليم اللغة العربية للناطقين بلغات أخرى. مكة. } \\
& \text { جامعة أم القرى. } 1917 . \\
& \text { الخولي، محمّد علي. الاختبارات اللغويّة . الأردن. دار الفلاح. . . . . . } \\
& \text { صيني والآخرون، محمود إسماعيل. العربية للناسئن. بيروت. مؤسسة سعيد الصباغ. } \\
& \text { جهول السنة. } \\
& \text { الفوزان، عبد الرحمن بن إبراهيم. إعلداد مواد تعليم اللغة العربيّة لغير الناطقين جا. مجهول }
\end{aligned}
$$

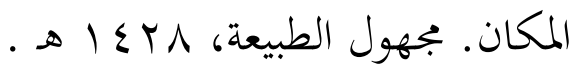

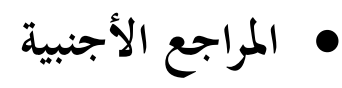

http://id.m.wikipedia.org/wiki/Kosakata

Agustin, Risa. Kamus Ilmiah Populer Lengkap. Surabaya. Serba Jaya. Tanpa Tahun. 